\section{Perkerasan Rigid di Wilayah Container Distribution Center Pelabuhan Trisakti untuk Tipe Kontainer 20 feet dan Alat Berat Reach Stacker tipe Kalmar DRT450}

Nissa Ayu

Staf Teknik di PT. Pelabuhan Indonesia III (Persero) Regional Kalimantan

nissa.ayu@pelindo.co.id
Perubahan fungsi lapangan penumpukan yang semula digunakan untuk peti kemas kosong menjadi penuh menyebabkan terjadinya kerusakan akibat ketidakmampuan konstruksi awal terhadap beban baru yang bekerja. Untuk itu diperlukan peningkatan fasilitas pelabuhan sebagai salah satu aksi untuk menciptakan nilai tambah yang berkelanjutan dan meningkatkan kepuasan stakeholder. Paper ini membahas mengenai peningkatan perkerasan rigid lantai lapangan penumpukan peti kemas sebagai fasilitas utama pelabuhan. Langkah-langkah yang dilakukan adalah survei kondisi lapangan eksisting, menentukan metode perbaikan yang sesuai dengan fungsi, berkoordinasi dengan pihak operasional, melakukan desain perkerasan dengan beban alat berat reach stacker dan peti kemas ukuran 20 feet, serta pelaksanaan dan pengawasan pekerjaan yang sesuai dengan syarat dan rencana kerja. Hasil desain dari peningkatan lapangan penumpukan tersebut adalah perkerasan rigid dengan Mutu Beton K-30o, tulangan Wiremesh M1o rangkap dan tebal lantai beton $300 \mathrm{~mm}$.

Kata kunci: perkerasan rigid, peti kemas, reach stacker, pelabuhan trisakti

Diajukan: 1 Juli 2019

Direvisi: 11 Juli 2019

Diterima:14 Juli 2019

Dipublikasikan online:15 Juli 2019

\section{Pendahuluan}

Lapangan penumpukan peti kemas adalah bagian penting dari Pelabuhan karena kegiatan bongkar muat peti kemas adalah salah satu bisnis utama pelabuhan, sehingga kondisi lapangan penumpukan tersebut harus sesuai dengan kriteria dan fungsinya.

Kerusakan yang terjadi di lapangan penumpukan harus segera diperbaiki karena kerusakan tersebut akan mengurangi produktivitas kegiatan operasional bongkar muat dan menjadi potensi bahaya serta kecelakaan kerja.

Proyek Pekerjaan Perbaikan Rigid Lantai Lapangan Penumpukan Peti Kemas Area CDC ini dilaksanakan dengan tujuan untuk mendukung kelancaran kegiatan operasional yang optimal khususnya untuk aktivitas bongkar muat peti kemas, meminialisir/mencegah kemungkinan terjadinya kecelakaan kerja (operasional) akibat kondisi lapangan penumpukan yang tidak layak dan memberikan pelayanan prima bagi pengguna jasa pelabuhan.

Kerusakan lapangan penumpukan yang terlihat pada Gambar 1 dan Gambar 2 adalah contoh kerusakan yang terjadi akibat adanya perubahan fungsi yang tidak disertai dengan perubahan desain perkerasan dari lapangan penumpukan untuk peti kemas empty (peti kemas kosong, tanpa muatan) menjadi lapangan penumpukan full (peti kemas dengan isi muatan).

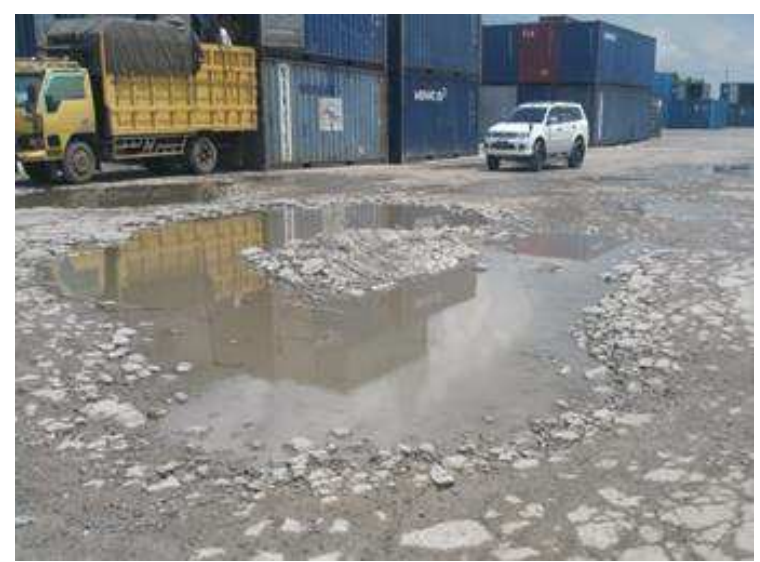

Gambar 1 Kondisi Eksisting Lapangan Penumpukan Area Utara

\section{Metode}

Metode yang digunakan dalam peningkatan lapangan penumpukan di area Lumba-lumba adalah perkerasan rigid dengan perhitungan desain berdasarkan literatur dari The Structural Design of Heavy Duty Pavement for 
Ports and Other Industries Edition 4. Penggunaan metode dan literatur tersebut berdasarkan pada cakupan yang sesuai dengan kondisi di lapangan khususnya Pelabuhan yang menggunakan beban peti kemas dan alat berat Reach Stacker dengan desain perkerasan Rigid.

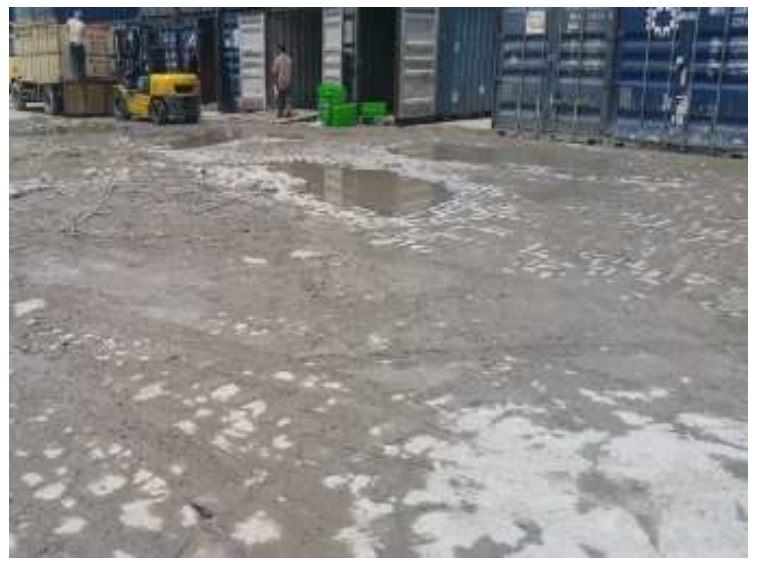

Gambar 2 Kondisi Eksisting Lapangan Penumpukan Area Timur

Perencanan desain dalam metode ini mempertimbangkan tanah dasar, variasi beban yang bekerja di Pelabuhan (besaran lalu lintas, tipe alat berat yang bekerja, beban peti kemas) yang di konversi menjadi Single Equivalent Wheel Load (SEWL), dan alternatif penggunaan material yang dapat ditentukan berdasarkan Material Equivalence Factors (MEFs). (Skar, 2014)

Desain perkerasan menggunakan beban utama alat berat berupa Reach Stacker tipe Kalmar DRT450 (sesuai dengan alat berat yang beroperasi di lapangan penumpukan). Beban Reach Stacker ditambah dengan beban peti kemas ukuran 20 feet dalam kondisi terisi penuh atau beban maksimal (Gambar 3).

Untuk tipe perkerasan yang diaplikasikan adalah perkerasan rigid beton yang disesuaikan dengan kondisi eksisting lapangan penumpukan agar

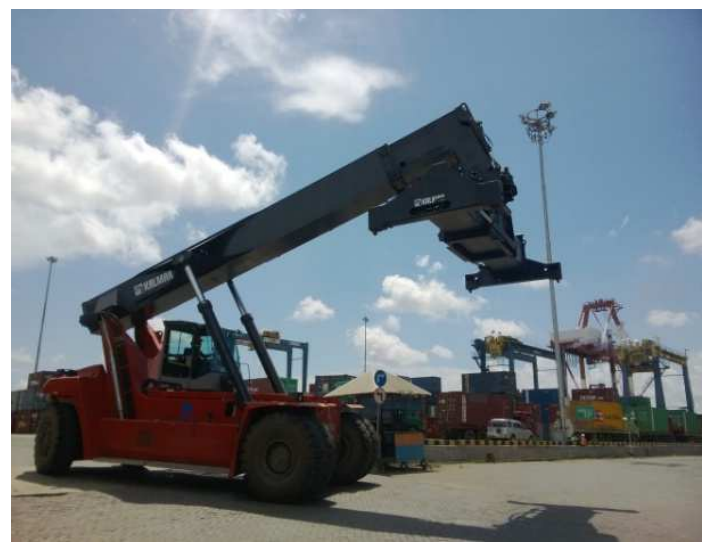

mempermudah pelaksanaan pekerjaan di lapangan. Area yang rusak dibongkar dengan kedalaman sesuai dengan tebal minimum hasil dari desain perkerasan.

\section{Hasil Kerja}

Kegiatan awal yang dilakukan sebelum pelaksanaan pekerjaan adalah survei kondisi kerusakan pada lapangan penumpukan dan mengambil keputusan langkah-langkah perbaikan yang harus dilakukan.

Pelaksanaan pekerjaan tersebut harus dikoordinasikan dengan pelaksana operasional karena sebagian area masih digunakan untuk kegiatan bongkar muat. Perbaikan dilakukan secara bertahap, yaitu membagi area menjadi 3 bagian dan perpindahan area dapat dilaksanakan setelah umur beton mencapai 28 hari.(SNI, 2002)

Jika dilihat dari Gambar 1 dan Gambar 2 serta desain awal lantai eksisting pada Gambar 4; tipe lapangan penumpukan adalah rigid lantai beton bertulang, sehingga diputuskan untuk menyesuaikan tipe tersebut untuk perbaikannya selanjutnya.

\section{Desain}

Beban yang bekerja pada lapangan penumpukan adalah beban sendiri Reach Stacker sebesar 69.5 ton (Cargotec, 2010) dan beban maksimum kontainer 20 feet sebesar 24 ton.

Berdasarkan Persamaan (1) dan (2) diperoleh beban statis roda maksimum sebesar 19.22 ton. Beban tersebut dirubah menjadi beban efektif statis roda dengan mengalikan faktor pendekatan yang diinterpolasi berdasarkan tebal efektif dan beban statis roda. Dari hasil tersebut didapat beban efektif statis roda 31.57 ton. Tahap selanjutnya adalah menentukan tebal minimum ( $8 / 10$ atau mutu $\mathrm{K}-100)$ yang digunakan untuk perencanaan berdasarkan beban dinamis kendaraan atau kapasitas lapangan penumpukan.

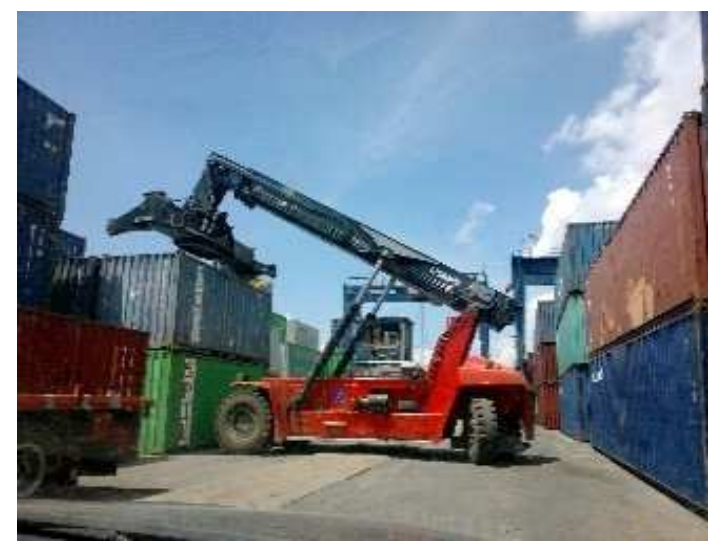

Gambar 3 Reach Stacker tipe Kalmar DRT450 dan Peti kemas ukuran 20 feet 


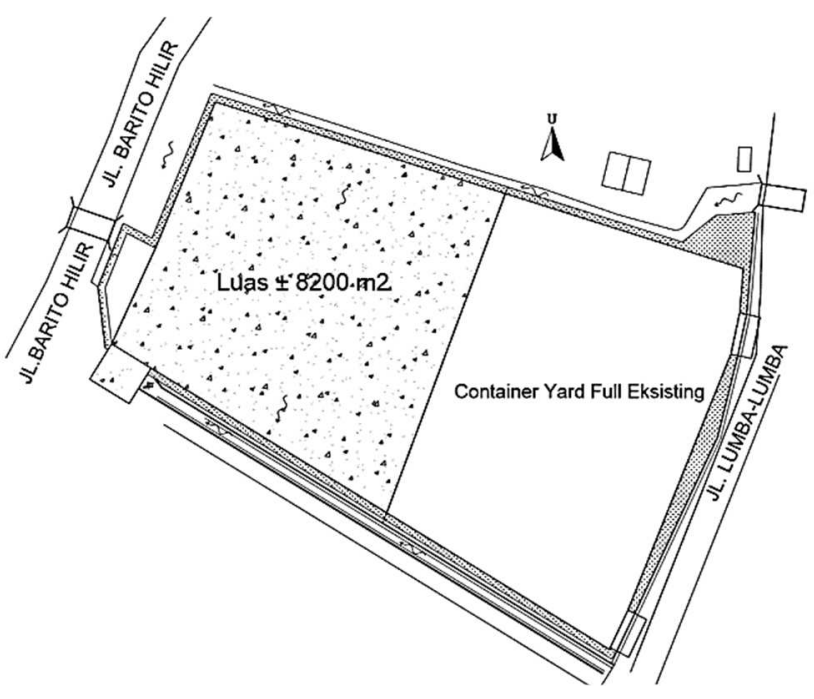

Layout Eksisting sebelum Kerusakan

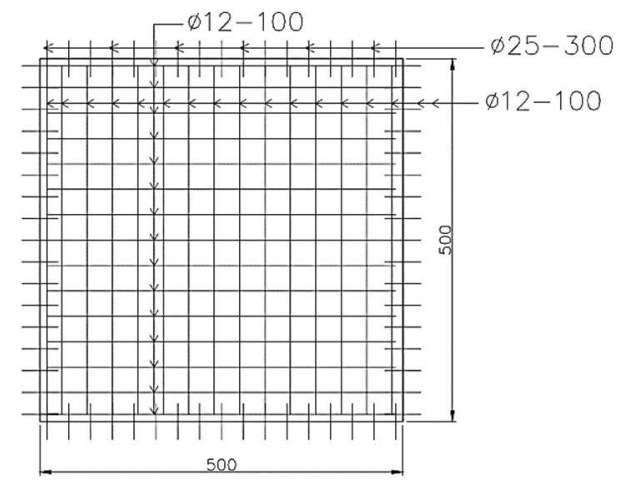

Penulangan Plat Beton

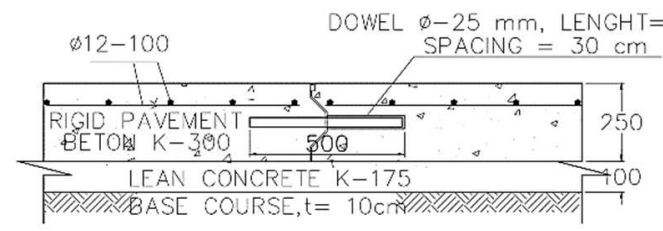

Potongan Memanjang Desain Eksisting sebelum Kerusakan

Gambar 4 Desain awal lapangan peti kemas di Pelabuhan Trisakti Banjarmasin

$$
\begin{aligned}
& W_{1}=f_{d} \times \frac{A_{1} \cdot W_{c}+B_{1}}{M} \\
& W_{2}=f_{d} \times \frac{A_{2} \cdot W_{c}+B_{2}}{2}
\end{aligned}
$$

Dimana $w_{1}$ dan $w_{2}$ adalah gaya-gaya yang bekerja pada roda reach stacker seperti terlihat pada Gambar 5.

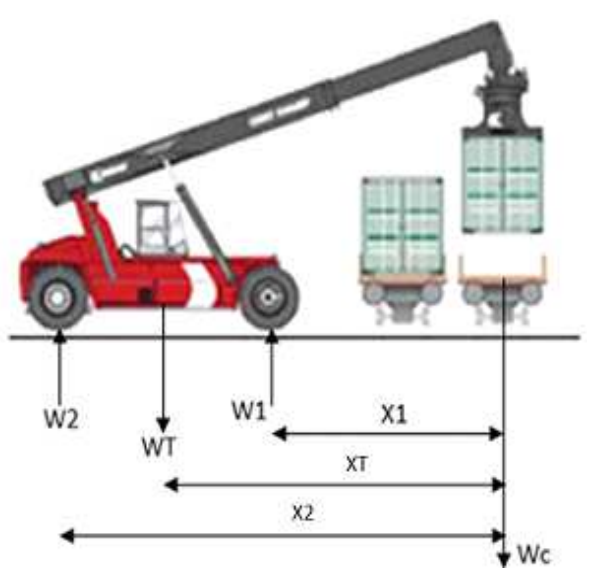

Gambar 5 Distribusi Pembebanan
Tabel 1 adalah tebal minimum yang harus digunakan dalam perencanaan. Berdasarkan Tabel 1, maka tebal mimimum yang digunakan adalah $680 \mathrm{~mm}$. Jika direncanakan dengan mutu beton K-300 dan tulangan yang digunakan adalah wiremesh M10 rangkap dua, maka dari hasil interpolasi yang disesuaikan dengan tabel korelasi material didapat hasil seperti terlihat pada Tabel 2.

Berdasarkan hasil dari Tabel 2, tebal minimum perkerasan adalah $283 \mathrm{~mm}$, sehingga desain yang digunakan adalah tebal beton $300 \mathrm{~mm}$ dengan mutu K300 dan Wiremesh M10 rangkap. Gambar rencana sebagai hasil perhitungan terlihat pada Gambar 6.

Tabel 1 Tebal Minimum (C8/10 atau K-100)

\begin{tabular}{lc}
\hline \multicolumn{1}{c}{ Kondisi Pembebanan } & $\begin{array}{c}\text { Tebal Minimum } \\
{[\mathrm{mm}]}\end{array}$ \\
\hline Beban dinamis Kendaraan & 500 \\
Kapasitas Lapangan Penumpukan & 680
\end{tabular}


http://dx.doi.org/10.20527/bpi.v2i1.37

Tabel 2 Tebal Minimum berdasarkan Material Konstruksi

\begin{tabular}{lcccc}
\hline $\begin{array}{c}\text { Material } \\
\text { Konstruksi }\end{array}$ & $\begin{array}{r}\text { Tulangan } \\
{\left[\mathrm{kg} / \mathrm{m}^{3}\right]}\end{array}$ & $\begin{array}{c}\text { Faktor } \\
\text { Material } \\
\text { Ekivalen }\end{array}$ & $\begin{array}{c}\text { Tebal } \\
\text { Minimum } \\
{[\mathrm{mm}]}\end{array}$ & Ket. \\
\hline $\mathrm{C} 8 / 10(\mathrm{~K}-100)$ & & 1.00 & 680 & $\begin{array}{c}\text { Tabel } \\
\text { MEF }\end{array}$ \\
$\begin{array}{l}\text { C25/30 (K-300) } \\
\text { C25/30 (K-300) }\end{array}$ & 30.00 & 0.55 & 374 & $\begin{array}{l}\text { Tabel } \\
\text { MEF }\end{array}$ \\
$\begin{array}{l}\text { C25/30 (K-300) } \\
\text { K-300 dan }\end{array}$ & 50.00 & 0.45 & 306 & $\begin{array}{c}\text { Tabel } \\
\text { wiremesh M10 }\end{array}$ \\
\begin{tabular}{l} 
rangkap \\
\hline
\end{tabular} & 56.76 & 0.42 & 283 & MEF \\
\hline
\end{tabular}

Ada terdapat beberapa perbedaan hasil desain awal dan desain baru yang dapat dilihat pada Tabel 3 .

\section{Pelaksanaan Pekerjaan}

Tahapan pelaksanaan pekerjaan dimulai dari penentuan area perbaikan sesuai dengan kondisi eksisting di lapangan. Dari hasil koordinasi dengan pihak operasional, area tersebut di bagi menjadi 3 bagian, Area I $(F, G, H)$, Area II (A,B C) dan Area III (D,E) (Gambar.6). Hal ini dilakukan karena sebagian area tersebut masih digunakan untuk kegiatan bongkar muat. Kemudian dilanjutkan dengan pembongkaran beton yang rusak menggunakan alat berat excavator agar pelaksanan lebih efektif dan efisien (Gambar 7).

Tabel 3 Perbandingan Hasil Desain

\begin{tabular}{lcc}
\hline \multicolumn{1}{c}{ Item } & $\begin{array}{c}\text { Desain awal } \\
\text { (sebelum } \\
\text { kerusakan) }\end{array}$ & $\begin{array}{c}\text { Desain } \\
\text { Perbaikan }\end{array}$ \\
\hline Tipe Tulangan & $\begin{array}{c}\varnothing 12 \\
\text { (tulangan polos) }\end{array}$ & $\begin{array}{c}\text { M10 } \\
\text { (wiremesh) }\end{array}$ \\
$\begin{array}{l}\text { Jarak antar tulang } \\
\text { (mm) }\end{array}$ & 100 & 150 \\
$\begin{array}{l}\text { TulanganTerpasang } \\
\text { (kg/m3) }\end{array}$ & 19.53 & 56.76 \\
$\begin{array}{l}\text { Mutu Beton } \\
\text { Tebal Perkerasan }\end{array}$ & K-300 & K-300 \\
$(\mathrm{mm})$ & 250 & 300
\end{tabular}

Pelaksanaan pengecoran di lapangan dalam satu area dibagi menjadi beberapa segmen dengan ukuran $5 \mathrm{~m} \times 5 \mathrm{~m}$ (Gambar 7) dengan pertimbangan agar memudahkan pekerjaan pengecoran, pemeliharaan dan kontrol mutu beton.

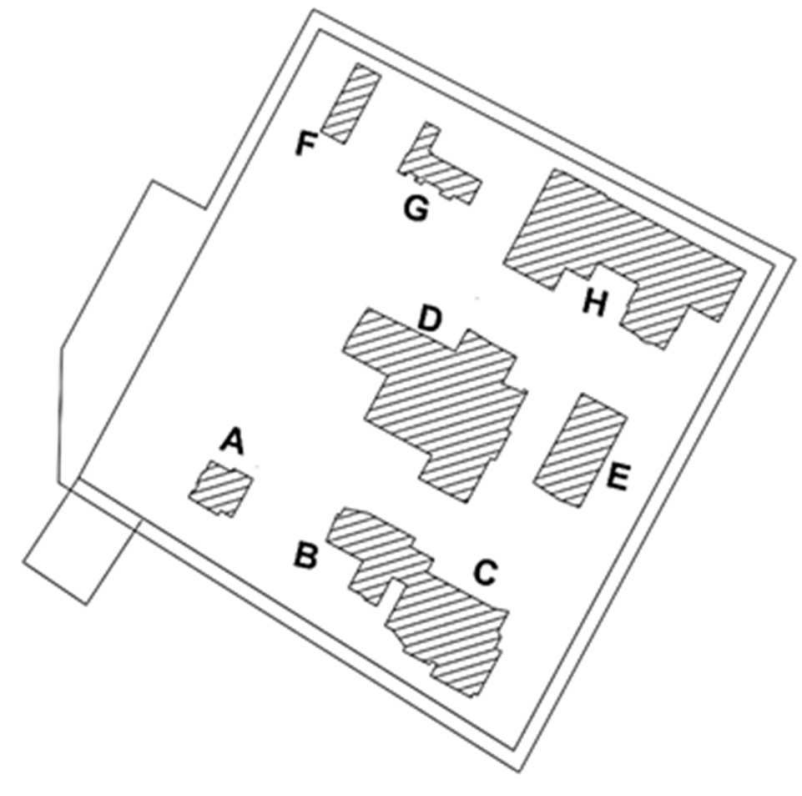

Layout perkerasan rigid

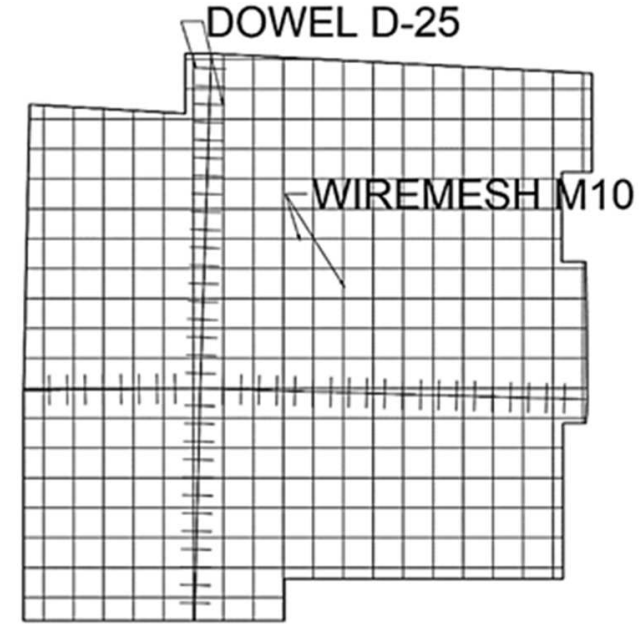

Penulangan segmen A

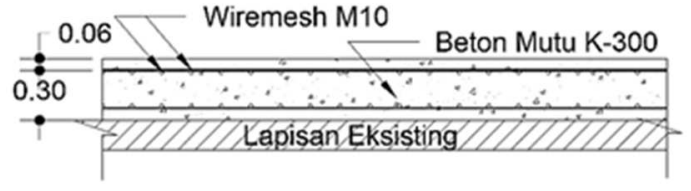

Potongan memanjang

Gambar 6 Desain awal lapangan peti kemas di Pelabuhan Trisakti Banjarmasin 


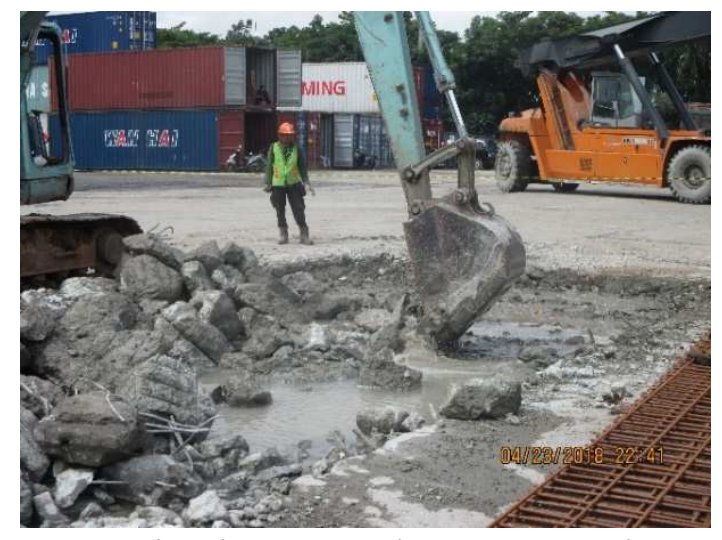

Pembongkaran Beton Eksisting yang Rusak

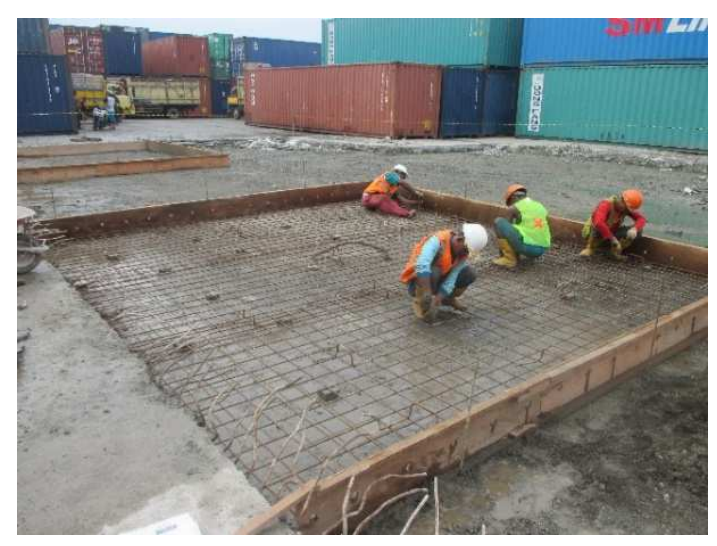

Pemasangan Wiremesh M10

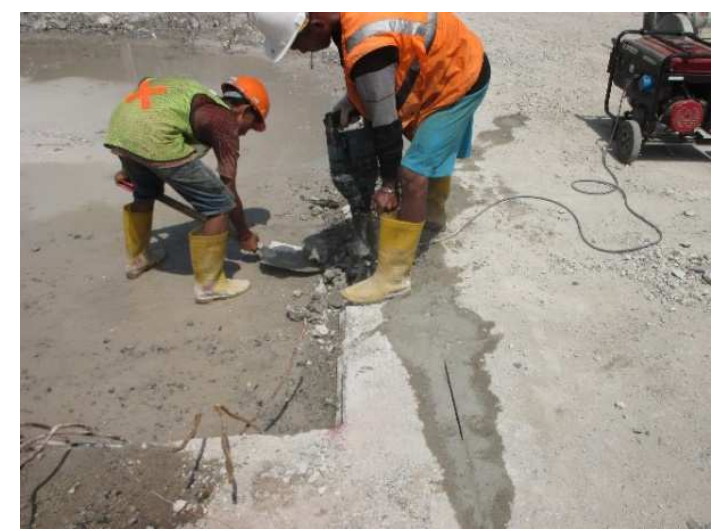

Perapian Dinding Beton Bekas Bongkaran

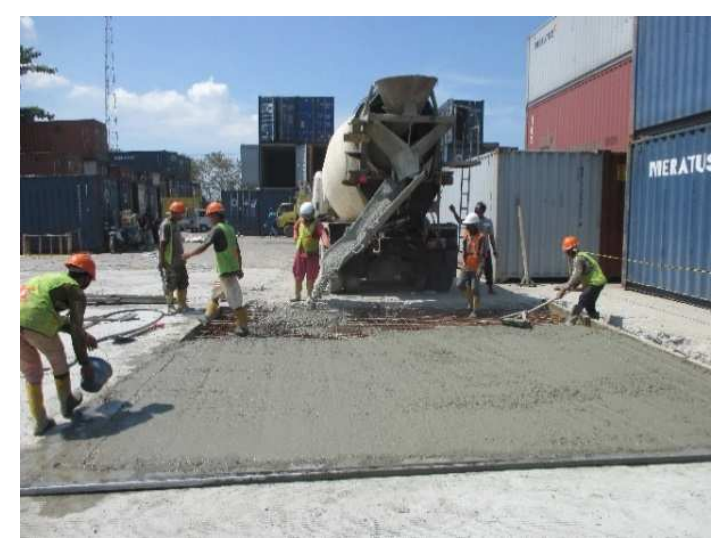

Pengecoran Beton Mutu K-300

Gambar 7 Pelaksanaan pekerjaan perbaikan lapangan petikemas CDC Pelabuhan Trisakti

\section{Kesimpulan}

Hasil peningkatan perkerasan rigid untuk Lapangan Penumpukan Peti Kemas untuk Tipe Kontainer 20 feet (full) dan Alat Berat Reach Stacker tipe Kalmar DRT450 adalah Mutu Beton K-300 dengan tulangan Wiremesh M10 rangkap dan tebal lantai beton $300 \mathrm{~mm}$ (Gambar 8).

Adanya perubahan beban yang bekerja pada lapangan penumpukan mempengaruhi desain akhir perkerasan dengan mutu beton yang sama, dari desain awal sebelum kerusakan tebal beton $250 \mathrm{~mm}$ menjadi $300 \mathrm{~mm}$ dan kebutuhan tulangan dari $19.53 \mathrm{~kg} / \mathrm{m} 3$ menjadi $56.76 \mathrm{~kg} / \mathrm{m}^{3}$.

\section{Ucapan Terimakasih}

Ucapan terimakasih ditujukan kepada PT. Pelabuhan Indonesia III (Persero) Regional Kalimantan sebagai pemilik Proyek Pekerjaan Perbaikan Rigid Lantai CY Lumba-Lumba di Pelabuhan Banjarmasin.

\section{Referensi}

Cargotec (2010) Technical Data Reachtackers 42-45 Tonnes. Forklift Trades Pty Limited, Sweden.

Knapton, J., (2007) The Structural Design of Heavy Duty Pavement for Ports and Other Industries Edition 4, Interpave, The Precast Concrete Paving and Kerb Association.

Skar, A., (2014) Design of Port- and Industrial Pavement. International Journal of Pavement Engineering, 1-4. doi:10.1080/10298436.2018.1483502

SNI 03-2847-2002 (2002) Tata Cara Perhitungan Struktur Beton untuk Bangunan Gedung. Bandung. 
http://dx.doi.org/10.20527/bpi.v2i1.37
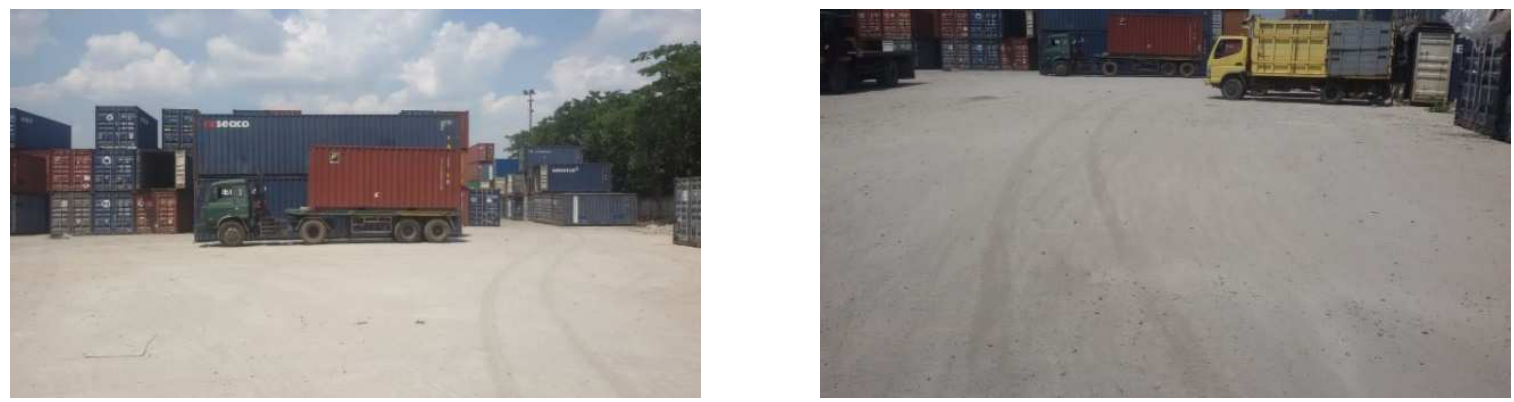

Gambar 8 Kondisi Lapangan Penumpukan setelah Perbaikan 